\title{
Tyrphostin A30
}

National Cancer Institute

\section{Source}

National Cancer Institute. Tyrphostin A30. NCI Thesaurus. Code C1666.

A potent protein tyrosine kinase inhibitor that exhibits greater specificity for c-ErbB oncoprotein. $(\mathrm{NCl})$ 